\title{
THE MODULATION OF DRUG EFFLUX TRANSPORTER BY CURCUMIN IN MCF7 BREAST CANCER CELLS AFTER REPEATED EXPOSURE OF ENDOXIFEN AND ESTRADIOL
}

\author{
ROBBY HERTANTO ${ }^{1}$, WILSON BASTIAN ${ }^{2}$, PARAMITA ${ }^{1}$, MELVA LOUISA ${ }^{1 *}$ \\ ${ }^{1}$ Department of Pharmacology and Therapeutics, Faculty of Medicine, Universitas Indonesia, Jakarta, 10430, Indonesia. ${ }^{2}$ Biomedical \\ Sciences Postgraduate Program, Faculty of Medicine, Universitas Indonesia, Jakarta, 10430, Indonesia. Email: melva.louisa@gmail.com
}

Received: 18 July 2018, Revised and Accepted: 15 November 2018

\section{ABSTRACT}

Objective: The aim of the present study was to determine whether curcumin (CM) can prevent drug sensitivity of breast cancer (BC) cells when E and $\beta$-E2 are administered together and whether the underlying mechanism involves modulation of drug efflux transporters.

Methods: MCF7 BC cells were treated with the vehicle only, E+ $\beta$-E2, or E+ $\beta-E 2+C M$ repeatedly for 8 weeks. Afterward, the cells were harvested, counted, and isolated for total RNA extraction. Total RNA was then processed into cDNA and further processed for the determination of mRNA expression patterns of drug efflux transporters (P-glycoprotein, BCRP, and MRP1)

Results: Decreased sensitivity of BC cells was shown by the increased cell viability of MCF7 cells after 8 weeks. This condition was accompanied with increased mRNA expression of P-glycoprotein, BCRP, and MRP1 in cells treated with E+ $\beta$-E2, as compared with the vehicle only. CM, administered in combination with $E+\beta-E 2$, resulted in decreased cell viability versus $E$ and $\beta$-E2 and also decreased in mRNA expression of P-glycoprotein, BCRP, and MRP1.

Conclusion: $\mathrm{CM}$ partially reversed the sensitivity loss of $\mathrm{BC}$ cells to $\mathrm{E}$ in the presence of $\beta$-E2 by modulating drug efflux transporters.

Keywords: Curcumin, Efflux transporters, Endoxifen, Estradiol.

(C) 2018 The Authors. Published by Innovare Academic Sciences Pvt Ltd. This is an open access article under the CC BY license (http://creativecommons. org/licenses/by/4. 0/) DOI: http://dx.doi.org/10.22159/ijap.2018.v10s1.21

\section{INTRODUCTION}

Breast cancer (BC) is the most common type of cancer in women. Treatments for $\mathrm{BC}$ include surgery, radiation therapy, endocrine therapy, and chemotherapy. For endocrine therapy, tamoxifen (TMX) is the most common estrogen receptor (ER) modulator prescribed for ER-positive BC [1].

TMX is metabolized by CYP3A4 and CYP2D6 into several metabolites, which include 4-hydroxy-TMX, N-desmethyl-TMX, and 4-hydroxy$\mathrm{N}$-desmethyl-TMX, which is also known as endoxifen (E) [2]. E is an active metabolite of TMX that has recently been developed as a new endocrine therapeutic agent for $\mathrm{BC}$ patients unresponsive to antiestrogen treatment [3]. E exerts its anticancer effects by degrading ER alpha, which leads to the inhibition of estrogen-induced BC cell proliferation [4]. However, BC cell resistance to endocrine treatment, including E, is likely to develop overtime [5-7].

Numerous mechanisms are responsible for the development of endocrine resistance, including downregulation of components in the ER signaling pathway, alterations to the cell cycle, crosstalk with growth factor signaling pathways, BC stem cells, and modulation of drug transporters $[6,8]$. A known mechanism of $\mathrm{BC}$ cell resistance to TMX is the overexpression of the drug efflux transporters P-glycoprotein, BCRP, MRP1, and MRP2 $[9,10]$. $E$ is also known as a P-glycoprotein substrate in vitro and in vivo [11]. Thus, $\mathrm{BC}$ cell resistance to $\mathrm{E}$ might also be due to the overexpression of various drug efflux transporters.

To overcome the emergence of the resistance phenomenon, many groups have attempted to generate inhibitors of drug efflux transporters [12]. Curcumin (CM), a natural diphenolic compound from Curcuma longa, exerts antiproliferative effects and modulates the activities of drug efflux transporters $[12,13]$. Therefore, the aim of the present study was to determine whether CM can prevent the decreased sensitivity of BC cells to $E$, when administered together with estradiol $(\beta-E 2)$ and whether the underlying mechanism involves modulation of drug efflux transporters.

\section{MATERIALS AND METHODS}

\section{Materials and reagents}

CM was purchased from Plamed Green Science Limited (Xi'an, China), $\mathrm{E}$ was purchased from Tocris Bioscience (Ellisville, MO, USA), and â-E2 was purchased from Sigma-Aldrich Pte. Ltd. (Singapore). Dimethyl sulfoxide (DMSO) was purchased from Vivantis Technologies Sdn Bhd (Malaysia). High-glucose Dulbecco's modified Eagle's medium (DMEM), heat-inactivated fetal bovine serum (FBS), penicillin/streptomycin, and fungizone were purchased from Biowest LLC (Riverside, MO, USA). The High Pure RNA Isolation Kit, Transcriptor First Strand cDNA Synthesis Kit, and FastStart DNA Master SYBR Green I were purchased from Roche Molecular Systems, Inc. (Pleasanton, CA, USA). Primers for P-glycoprotein, BCRP, MRP1, and â-actin were purchased from $1^{\text {st }}$ BASE Pte Ltd. (Singapore).

\section{Cell culture}

MCF-7 BC cells were kindly provided by Makmal Terpadu Laboratory, Faculty of Medicine, Universitas Indonesia. The cells were maintained in DMEM high glucose supplemented with $10 \%$ FBS, $10 \mathrm{U} / \mathrm{mL}$ penicillin, $100 \mu \mathrm{g} / \mathrm{mL}$ streptomycin, and $2.5 \mu \mathrm{g} / \mathrm{mL}$ fungizone at $37^{\circ} \mathrm{C}$ in a humidified atmosphere of $5 \% \mathrm{CO}_{2}$.

\section{Drug preparation}

E, $\beta$-E2, and CM were diluted in DMEM to the desired concentrations. A DMSO concentration of $<0.001 \%$ was used as a negative control throughout this study.

\section{Drug treatment}

MCF7 cells were seeded into the wells of a 6-well plate at 10,000 cells per well and further treated with control (DMSO) or E $1 \mu \mathrm{M}$, E 1 
$\mu \mathrm{M}+\beta$-E2 $1 \mathrm{nM}, \mathrm{E} 1 \mu \mathrm{M}+\beta-\mathrm{E} 21 \mathrm{nM}+\mathrm{CM} 8.5 \mu \mathrm{M}$, or E $1 \mu \mathrm{M}+\beta$-E $21 \mathrm{nM}+\mathrm{CM}$ $17 \mu \mathrm{M} 3$ times weekly for 8 weeks. The cells were passaged every week following trypsinization and counting. Afterward, 10,000 cells were replated in complete medium for $72 \mathrm{~h}$ before the addition of drugs. Each treatment was conducted 3 times in duplicate.

\section{Cell viability assay}

Cell viability was determined using the trypan blue dye exclusion assay. The number of viable cells was counted using a hemocytometer. The results are expressed as the percentage relative to the control cells.

Quantitative reverse transcriptase polymerase chain reaction (qRT-PCR) analysis

Total cellular RNA was extracted from cell pellets using the high pure RNA isolation kit in accordance with the manufacturer's protocol. RNA $(1 \mu \mathrm{g}$ in $20 \mu \mathrm{L})$ was converted to cDNA using the Transcriptor First Strand cDNA Synthesis kit. qRT-PCR was performed using the FastStart DNA Master SYBR Green I kit, according to the manufacturer's protocol, with $\beta$-actin as the housekeeping gene, and qRT-PCR was performed with the following primers: $\beta$-actin (F: $5^{\prime}$-TTC GGC TTG CAA CAA CTA TG-3'; R: 5'-TCC AGA CAC ACC ACG GAT AA-3'), P-glycoprotein (F: 5'-TTA CAT TCA GGT TTC ATT TTG GTG-3', R: $5^{\prime}$-TTC TGT CGC ATT ATA GCA TGA-3'), BCRP (F: 5'-TTC GGC TTG CAA CAA CTA TG-3'; R: 5'-TCC AGA CAC ACC ACG GAT AA-3'), and MRP1 (F: $5^{\prime}$-ATG TCA CGT GGC CTA CCA GC-3'; R: 5'-GAA GAC TGA ACT CCC TTC CG-3').

The total reaction volume was $20 \mu \mathrm{L}$. Reactions were performed in a 32-well plate using a LightCycler ${ }^{\circledR}$ Nano Instrument (F. HoffmannLa Roche Ltd., Basel, Switzerland) with the following cycling conditions: $95^{\circ} \mathrm{C}$ for $10 \mathrm{~min}$, followed by 45 cycles at $95^{\circ} \mathrm{C}$ for 20 $\mathrm{s}$ and annealing temperature of $55^{\circ} \mathrm{C}$ for $1 \mathrm{~min}$ for $\beta$-actin or $53^{\circ} \mathrm{C}$ for $20 \mathrm{~s}$ for P-glycoprotein, MRP1, and BCRP. The raw quantification cycle $(\mathrm{Cq})$ values were analyzed by relative quantification using the Livak method to determine normalized expression ratios of target genes.

\section{Data analysis}

Data were analyzed by one-way analysis of variance followed by the Tukey method, with $\alpha=0.05$, and are presented as the mean \pm standard deviation. All statistical analyses were performed with GraphPad Prism 6 software (GraphPad Software, Inc., La Jolla, CA, USA).

\section{RESULTS}

$E$ in the presence of $\beta$-E2 showed good control of cell viability in the $1^{\text {st }}$ week of drug treatment. Concomitant treatment with $\mathrm{E}$ and $\mathrm{CM}$ in the presence of $\beta$-E2 showed a synergistic effect, with additional suppression of cell viability (Fig. 1). However, after 8 weeks of treatment with $\mathrm{E}$ and $\beta$-E2, the efficacy of $\mathrm{E}$ was clearly lost, as $\mathrm{BC}$ cell viability had surpassed that of the control cells. Concomitant treatment with a low concentration of CM did not improve the sensitivity of BC cells to $\mathrm{E}$, whereas larger concentrations showed good suppression of cell viability after 8 weeks of treatment (Fig. 1).

P-glycoprotein mRNA analysis showed that continuous treatment with $\mathrm{E}+\beta$-E2 resulted in increased expression, whereas concomitant treatment with CM both at low and high concentrations reversed expression levels back to normal (Fig. 2).

BCRP mRNA expression was also increased after 8 weeks of treatment with $\mathrm{E}$ and $\beta$-E2. $\mathrm{CM}$ at both concentrations was shown to suppress BCRP mRNA expression but not potent enough to reverse expression back to control values (Fig. 3).

Continuous treatment with $\mathrm{E}$ in the presence of $\beta$-E2 was also shown to increase MRP1 mRNA expression. However, lower concentrations of CM failed to suppress the increased expression of MRP1, whereas CM at higher concentrations tended to suppress MRP1 mRNA expression, but the effect was not sufficiently potent (Fig. 4).

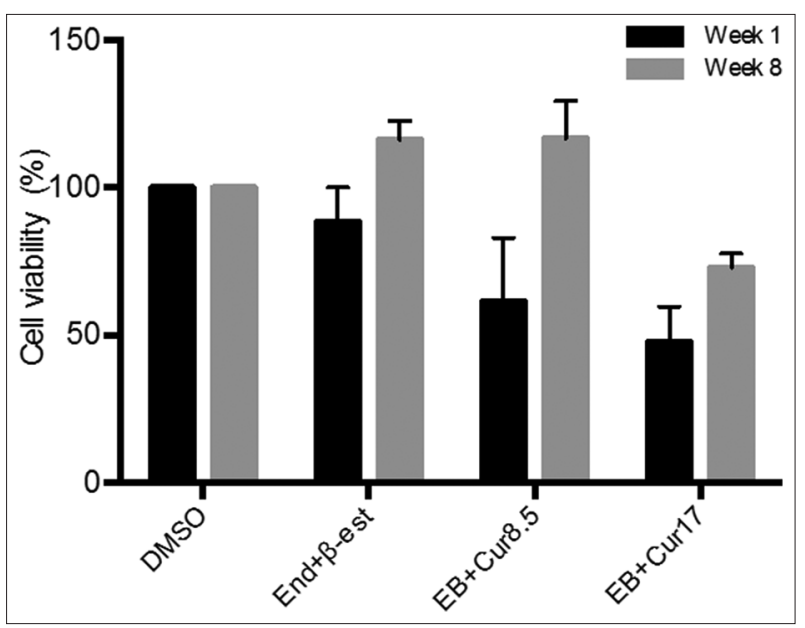

Fig. 1: Cell viability after MCF7 treatment with dimethyl sulfoxide or $E+\beta-E 2$ or $E+\beta-E 2+C M 8.5 \mu M$ or $E+\beta-E 2+C M 17 \mu M$ for 8 weeks. End $+\beta-\mathrm{E} 2=\mathrm{E} 1 \mu \mathrm{M}+\beta-\mathrm{E} 21 \mathrm{nM}, \mathrm{EB}+\mathrm{CM} 8.5=\mathrm{E} 1 \mu \mathrm{M}+\beta-\mathrm{E} 21 \mathrm{nM}+\mathrm{CM}$ $8.5 \mu \mathrm{M}, \mathrm{EB}+\mathrm{CM} 17=\mathrm{E} 1 \mu \mathrm{M}+\beta-\mathrm{E} 21 \mathrm{nM}+\mathrm{CM} 17 \mu \mathrm{M}$

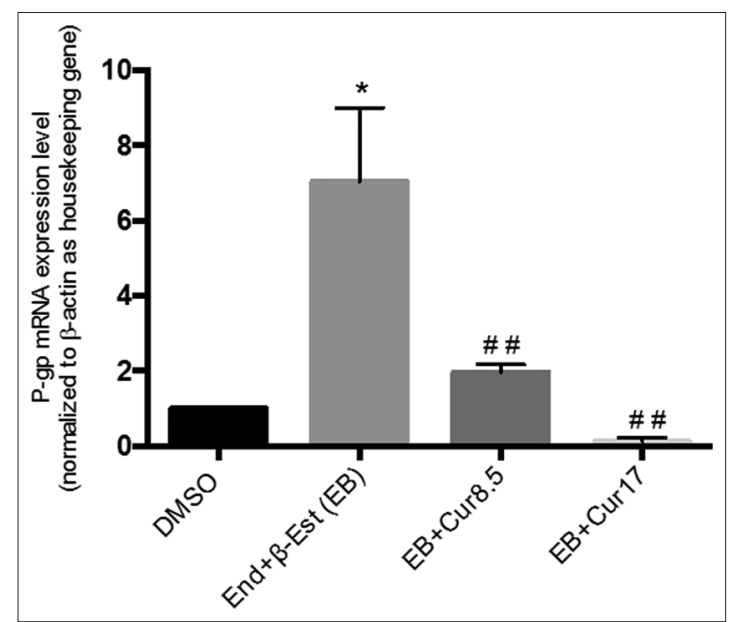

Fig. 2: P-glycoprotein mRNA expression after MCF7 treatment with dimethyl sulfoxide or $E+\beta-E 2$ or $E+\beta-E 2+C M \quad 8.5 \mu M$ or $E+\beta$ E2+CM $17 \mu$ for 8 weeks. *Significantly different from DMSO at $p<0.05$; \#\#significantly different from $E+\beta-E 2$ at $p<0.001$. End + $\beta-\mathrm{E} 2=\mathrm{E} 1 \mu \mathrm{M}+\beta-\mathrm{E} 21 \mathrm{nM}, \mathrm{EB}+\mathrm{CM} 8.5=\mathrm{E} 1 \mu \mathrm{M}+\beta-\mathrm{E} 21 \mathrm{nM}+\mathrm{CM}$ $8.5 \mu \mathrm{M}, \mathrm{EB}+\mathrm{CM} 17$ = E $1 \mu \mathrm{M}+\beta-\mathrm{E} 21 \mathrm{nM}+\mathrm{CM} 17 \mu \mathrm{M}$

\section{DISCUSSION}

Endocrine therapy is the most effective treatment for patients with ERpositive BC. However, treatment effectiveness is limited by high rates of de novo and acquired resistance during treatment [8]. E, an active metabolite of TMX, can also fail because of acquired resistance [6,7]. Hence, the aim of the present study was to determine the efficacy of $\mathrm{CM}$ administered for the prevention of decreased sensitivity of BC cells to $\mathrm{E}$ by coadministration with $\beta$-E2.

The efficacy of $\mathrm{E}$ on cell viability was lost after treatment for 8 weeks. $\mathrm{E}$ is a new drug under development for the treatment of advanced $\mathrm{BC}$; thus, few studies have investigated the mechanism of $\mathrm{E}$ resistance.

Several studies have argued that epithelial-mesenchymal transition, which is characterized by increased vimentin expression, might play a significant role in the development of E resistance [7]. In addition, Squirewell et al. [14] argued that E may affect the ability of human 


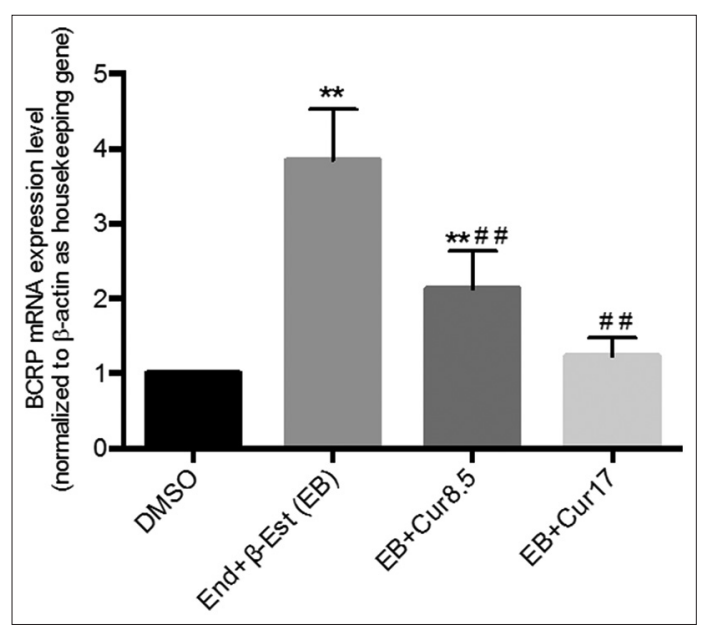

Fig. 3: BCRP mRNA expression after MCF7 treatment with dimethyl sulfoxide or $E+\beta-E 2$ or $E+\beta-E 2+C M 8.5 \mu M$ or $E+\beta$ E2+CM $17 \mu \mathrm{M}$ for 8 weeks. **Significantly different from DMSO at $\mathbf{p}<0.001$; \#\#significantly different from $E+\beta-E 2$ at $p<0.001$.

End $+\beta$-est $=\mathrm{E} 1 \mu \mathrm{M}+\beta$-E2 $1 \mathrm{nM}, \mathrm{EB}+\mathrm{CM} 8.5=\mathrm{E} 1 \mu \mathrm{M}+\beta$-E2

$1 \mathrm{nM}+\mathrm{CM} 8.5 \mu \mathrm{M}, \mathrm{EB}+\mathrm{CM} 17$ = E $1 \mu \mathrm{M}+\beta-\mathrm{E} 21 \mathrm{nM}+\mathrm{CM} 17 \mu \mathrm{M}$

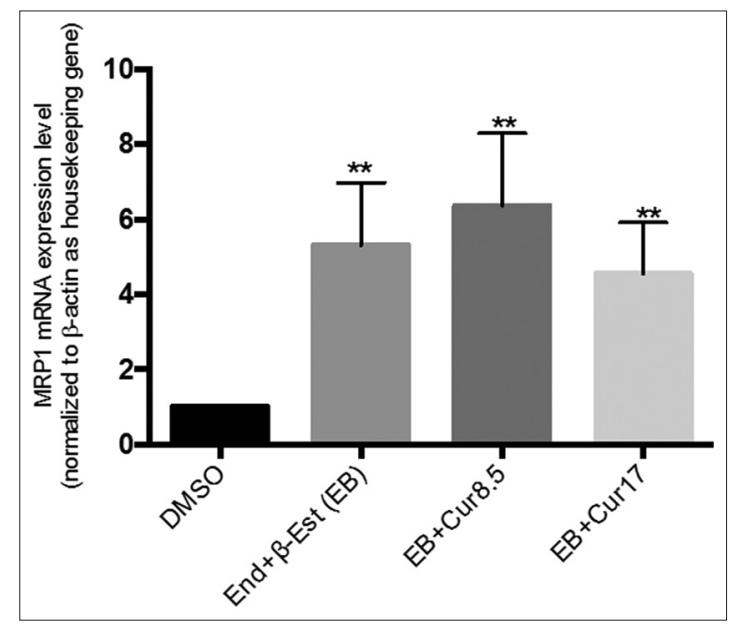

Fig. 4: MRP1 mRNA expression after MCF7 treatment with dimethyl sulfoxide (DMSO) or E+ $\beta$-E2 or E+ $\beta$-E2 + CM $8.5 \mu \mathrm{M}$ or $\mathrm{E}+\boldsymbol{\beta}-\mathrm{E} 2+\mathrm{CM} 17 \mu \mathrm{M}$ for 8 weeks. ${ }^{*}$ Significantly different from DMSO at $p<0.001$; \#\#significantly different from $E+\beta$-E2 at $p<0.001$. End $+\beta$-est $=\mathrm{E} 1 \mu \mathrm{M}+\beta$-E2 $1 \mathrm{nM}, \mathrm{EB}+\mathrm{CM} 8.5=\mathrm{E} 1$ $\mu \mathrm{M}+\beta-\mathrm{E} 21 \mathrm{nM}+\mathrm{CM} 8.5 \mu \mathrm{M}, \mathrm{EB}+\mathrm{CM} 17=\mathrm{E} 1 \mu \mathrm{M}+\beta-\mathrm{E} 21 \mathrm{nM}+\mathrm{CM}$ $17 \mu \mathrm{M}$

estrogen sulfotransferase $1 \mathrm{E} 1$ and human phenol sulfotransferase $1 \mathrm{~A} 1$ isoform 1 to catalyze the sulfation of $\beta$-E2, which plays important roles in the termination of estrogen signaling through the loss of ER activity.

Drug efflux transporters are involved in the decreased sensitivity of $\mathrm{BC}$ cells to TMX $[9,10]$. In the present study, the sensitivity of $\mathrm{BC}$ cells to $\mathrm{E}$ was diminished, which was followed by increased activities of the drug efflux transporters P-glycoprotein, BCRP, and MRP1. According to Teft et al. [15], E is a substrate of P-glycoprotein (multidrug resistance 1). However, it remains unclear as to whether $\mathrm{E}$ induces or inhibits P-glycoprotein expression.

$\mathrm{CM}$, a polyphenol derived from $C$. longa, has a wide range of beneficial properties as a chemotherapeutic agent and modulator of $\mathrm{ABC}$ efflux transporters [12,13]. A recent study also showed that $\mathrm{CM}$ administered together with TMX increased the anticancer activity, as compared with TMX alone. This effect may occur through the suppression of
P-glycoprotein (MDR1) expression [16-18]. Squirewell et al. [14] proposed a mechanism of the interactions of polyphenols, including $C M$, with $\mathrm{ABC}$ transporters and showed that polyphenols counteracted tumor cell chemoresistance by interacting with the ATP-binding domains of P-glycoprotein and inhibits its ATPase activity site and steroid interacting regions of the protein cytosolic domains [13]. However, for a flavonoid to interact with MRP1, it also needs transport stimulation of reduced glutathione $[1,19]$. This phenomenon might explain the different patterns of CM effects in regard to P-glycoprotein, BCRP, and MRP1.

Low-concentration CM failed to reverse the decreased sensitivity of E, even when mRNA expression levels of P-glycoprotein and BCRP were significantly decreased. This finding suggests that MRP1 expression might be the most consistent match with cell viability. Hence, MRP1 might be the dominant transporter in the development of decreased sensitivity of BC cells to $\mathrm{E}$.

\section{CONCLUSION}

CM partially reversed the loss of sensitivity of $\mathrm{BC}$ cells to $\mathrm{E}$ in the presence of $\beta$-E2 by modulation of the drug efflux transporters P-glycoprotein, BCRP, and MRP1. CM should be further investigated as a drug candidate for the prevention of $\mathrm{E}$ resistance in $\mathrm{BC}$. However, further studies are needed to elucidate the underlying mechanisms.

\section{CONFLICTS OF INTEREST}

All authors have none to declare.

\section{REFERENCES}

1. Mao C, Yang ZY, He BF, Liu S, Zhou JH, Luo RC, et al. Toremifene versus tamoxifen for advanced breast cancer. Cochrane Database Syst Rev 2012;11:CD008926.

2. Desta Z, Ward BA, Soukhova NV, Flockhart DA. Comprehensive evaluation of tamoxifen sequential biotransformation by the human cytochrome P450 system in vitro: Prominent roles for CYP3A and CYP2D6. J Pharmacol Exp Ther 2004;310:1062-75.

3. Wu X, Hawse JR, Subramaniam M, Goetz MP, Ingle JN, Spelsberg TC, et al. The tamoxifen metabolite, endoxifen, is a potent antiestrogen that targets estrogen receptor alpha for degradation in breast cancer cells. Cancer Res 2009;69:1722-7.

4. Hawse JR, Subramaniam M, Cicek M, Wu X, Gingery A, Grygo SB, et al. Endoxifen's molecular mechanisms of action are concentration dependent and different than that of other anti-estrogens. PLoS One 2013;8:e54613.

5. Dixon JM. Endocrine resistance in breast cancer. N J Sci 2014;2014:1-27.

6. Hawse JR, Subramaniam M, Wu X, Negron V, Muzaffer C, Lingle WL, et al. Abstract PD05-11: Development, characterization, and effective in vitro treatment of an endoxifen resistant breast cancer cell line. Cancer Res 2010;70:PD05-11

7. Paramita $P$, Louisa $M$, Nafrialdi $N$. Increased vimentin mRNA expression in MCF-7 breast cancer cell line after repeated endoxifentreatment. Med J Indones 2016;25:207-13.

8. Osborne CK, Schiff R. Mechanisms of endocrine resistance in breast cancer. Annu Rev Med 2011;62:233-47.

9. Krisnamurti DG, Louisa M, Anggraeni E, Wanandi SI. Drug efflux transporters are overexpressed in short-term tamoxifen-induced MCF7 breast cancer cells. Adv Pharmacol Sci 2016;2016:6702424.

10. Choi HK, Yang JW, Roh SH, Han CY, Kang KW. Induction of multidrug resistance associated protein 2 in tamoxifen-resistant breast cancer cells. J Pharmacol Exp Ther 2002;302:407-15.

11. Iusuf D, Teunissen SF, Wagenaar E, Rosing H, Beijnen JH, Schinkel AH, et al. P-glycoprotein (ABCB1) transports the primary active tamoxifen metabolites endoxifen and 4-hydroxytamoxifen and restricts their brain penetration. J Pharmacol Exp Ther 2011;337:710-7.

12. Xue X, Yu JL, Sun DQ, Zhou W, Kong F, Wu J, et al. Curcumin as a multidrug resistance modulator-a quick review. Biomed Prev Nutr 2013;3:173-6.

13. Hatcher H, Planalp R, Cho J, Torti FM, Torti SV. Curcumin: From ancient medicine to current clinical trials. Cell Mol Life Sci 2008;65:1631-52.

14. Squirewell EJ, Duffel MW. The effects of endoxifen and other major metabolites of tamoxifen on the sulfation of estradiol catalyzed by human cytosolic sulfotransferases hSULT1E1 and hSULT1A11. Drug Metab Dispos 2015;43:843-50 
15. Teft WA, Mansell SE, Kim RB. Endoxifen, the active metabolite of tamoxifen, is a substrate of the efflux transporter P-glycoprotein (multidrug resistance 1). Drug Metab Dispos 2011;39:558-62.

16. Louisa M, Sugiarti L, Kurniawan SV, Wanandi SI. Curcumin increases anti-cancer activity of tamoxifen in MCF-7 breast cancer cells through the suppression of MDR1 mRNA expression. Adv Sci Lett 2017;23:6838-40.

17. Alavala RR, Katahala P, Thipparapu G, Kulandaivelu U, Boyapati S,
Mantripragada BR. Study in vivo pharmacokinetic drug interactions of curcumin on tacrine. Asian J Pharm Clin Res 2018;11:337-43.

18. Gadekar R, Saurabh MK, Thakur GS, Saurabh A. Study of formulation, characterisation and wound potential of transdermal patches of curcumin. Asian J Pharm Clin Res 2012;5:225-30.

19. Leslie EM, Deeley RG, Cole SP. Bioflavonoid stimulation of glutathione transport by the 190-kDa multidrug resistance protein 1 (MRP1). Drug Metab Dispos 2003;31:11-5. 